\title{
Non-cancer effects of exposure to A-bomb radiation
}

\author{
A M STEWART AND G W KNEALE
}

From the Department of Social Medicine, University of Birmingham, Edgbaston, Birmingham B15 2TH, UK

SUMMARY A slight rearrangement of the data included in a recent report from the Radiation Effects Research Foundation (RERF) has shown differences between cardiovascular and other non-malignant diseases of A-bomb survivors which probably result from two factors: selection effects of early infection deaths and residual effects of marrow damage. Both effects were dose related but neither was obvious becasue one reduced the risk of later infection deaths and the other increased the risk. Allowance for these factors is bound to alter present RERF estimates for cancer effects of radiation and the change will probably be in an upward direction, thus bringing these estimates closer to ones based on radiation workers.

It is widely believed that in less than five years after exposure to tissue destructive doses of ionising radiations there will be (apart from cancer) no further life shortening effects of the radiation. This belief is based on the mortality experiences of Abomb survivors as interpreted by epidemiologists on the staff of the Radiation Effects Research Foundation (RERF) ${ }^{1-3}$ The RERF study population of survivors was assembled five years after the bombing of Hiroshima and Nagasaki and is a source of risk estimates of cancer effects of radiation that are incorporated in ICRP recommendations (International Commission on Radiation Protection), ${ }^{4}$ but are very different from much higher estimates based on a survey of American workers in the nuclear industry. ${ }^{5}$ Therefore, if there has been faulty interpretation of the Japanese data there will be many ramifications.

All published analyses of RERF data implicitly assume a monotone dose effect curve for all causes of mortality. This means that no one has been prepared to consider the possibility of any dose response curve having oppositely directed slopes at high and low dose levels as a result of survivors with high and low doses having different reactions to, say, infections. This possibility was first mentioned in a recent review of RERF publications, ${ }^{6}$ and, in subsequent correspondence, ${ }^{7}$ attention was drawn to the fact that for several groups of non-cancer deaths included in the 8 th mortality report ${ }^{2}$ there was evidence of a significant dip in the middle of the dose response curve. In other words the dose effect curve appeared to be U-shaped (with a small linear component) but most of the significant heterogeneity observed was the result of a strong quadratic component. This shape of curve was much more strongly suggested by deaths from tuberculosis (and a residual group containing other respiratory infections) than by deaths from cardiovascular diseases. It was possible, $\sigma-$ therefore, that the early epidemic of acute bone $c$ marrow depression ${ }^{8}$ was the cause of residual lesions 0 that had prevented full expression of a more $\vec{A}$ widespread effect-namely, selective survival of exceptionally hardy individuals during the immediate $\stackrel{+}{\perp}$ aftermath of the nuclear explosions.

\section{Data sources}

The following test of this hypothesis was necessarily based on published data and was, in fact, based on the 9th report since this includes a set of supplementary tables described as computer printouts containing LSS (Life Span Study) data from 1950 to $1978 .^{3}$ Included in this section of the 9th report are more than 600 tables that show, for eight dose levels and seven follow up periods, how observed deaths from various causes compare with expectations based on the assumption of no radiation effects. For example, if all the 1950-78 deaths were classified as cancers or non-cancers they would appear in the formation that has allowed all RERF analyses of deaths after September 1950 to be interpreted as evidence of no late effects of the radiation apart from cancer (table 1 and fig 1).

In table 2 deaths from diseases other than neoplasms (which could be divided only into the six groups shown in the footnote) are shown as two diagnostic groups (cardiovascular and other) and 
deaths in 1950-62 are shown separately from later deaths (1963-78). With this arrangement of the data (shown graphically in figs 2 and 3 ) it was possible to recognise differences between earlier and later deaths which find their strongest expression in the group that includes tuberculosis and other infection deaths. For this group, one of the two curves produced by plotting ratios of observed to expected deaths is deeply indented (1950-62 deaths) and the other is suggestive of a threshold dose effect (1963-78). Therefore, although we were in no position to determine the precise statistical parameters of the dose response curves for all



Fig 1 A-bomb survivor deaths 1950-78: cancer and noncancer. infection deaths in consequtive years (as RERF could by access to unpublished data), we have attempted a second best by subjecting the ratios of observed to expected deaths in table 3 to the following rank tests for linear and quadratic components of dose response.

\section{Method}

Provided that a variable has several levels (n) indexed by $\mathrm{i}$ we may define a generalised Spearman's rank correlation coefficient $(r)$ by the formula:

$$
\mathbf{r}=\frac{\mathbf{S}-\mathbf{M}}{\sqrt{\mathbf{V}}}
$$

where

$$
\begin{aligned}
& S=\Sigma W_{i} \cdot R_{i} ; M=\frac{(n+1) .}{2} \Sigma W_{i} ; \\
& \text { and } V=\left[\Sigma W_{i}-\frac{\left(\Sigma W_{i}\right)^{2}}{n}\right] \cdot n \cdot \frac{\left(n^{2}-1\right)}{12}
\end{aligned}
$$

and $S$ and $M$ are the observed and expected scores of the ranking numbers; $V$ is related to the variance of $r$ and $S ; W_{i}$ are weights, and $R_{i}$ is the rank at level $i$.

Under these conditions the variance of $r$ is $\frac{1}{n-1}$ and the variance of $S$ is $\frac{V}{n-1}$ Also the normal approximation to the distribution of $\mathbf{S}$ is improved if several such values are summated together with their variances. ${ }^{9}$ Therefore, we could make good use of the fact that for each cause of death listed in the RERF report there was a full complement of data for seven consecutive periods.

All that was necessary was to give the ratios in table 3 their ranking positions (table 4 ) and have two

\begin{tabular}{|c|c|c|c|c|c|c|}
\hline \multirow[b]{2}{*}{ Dose levels (rads) } & \multicolumn{3}{|c|}{ Cancer deaths* } & \multicolumn{3}{|c|}{ Non-cancer deaths } \\
\hline & Observed & Expected ${ }^{\dagger}$ & Ratio & Observed & Expected $\dagger$ & Ratio \\
\hline $\begin{array}{c}0 \\
1-9 \\
10-49 \\
50-99 \\
100-299 \\
200-299 \\
300-399 \\
\geqslant 400\end{array}$ & $\begin{array}{r}1896 \\
1320 \\
966 \\
281 \\
231 \\
132 \\
56 \\
100\end{array}$ & $\begin{array}{r}2009.6 \\
1388 \cdot 0 \\
948 \cdot 3 \\
276.3 \\
193.1 \\
79.2 \\
36.5 \\
50.9\end{array}$ & $\begin{array}{l}0.94 \\
0.95 \\
1.02 \\
1.02 \\
1.20 \\
1.67 \\
1.53 \\
1.96\end{array}$ & $\begin{array}{r}7534 \\
5248 \\
3506 \\
994 \\
652 \\
258 \\
132 \\
196\end{array}$ & $\begin{array}{r}7410 \cdot 1 \\
5241 \cdot 5 \\
3574 \cdot 3 \\
1029 \cdot 1 \\
683 \cdot 0 \\
282 \cdot 5 \\
127 \cdot 2 \\
174 \cdot 3\end{array}$ & $\begin{array}{l}1.01 \\
1.00 \\
0.98 \\
0.97 \\
0.96 \\
0.91 \\
1.04 \\
1.12\end{array}$ \\
\hline$\Sigma$ & \multicolumn{3}{|c|}{4982} & \multicolumn{3}{|c|}{18520} \\
\hline
\end{tabular}
choices of weights: one for when the rank

Table 1 Ratios of observed to expected deaths in eight dose groups. Cancer and non-cancer 1950-78

ICD Nos (8th revision) 140-239.

†Assuming no radiation effect with control for sex, city, exposure, age, and date of death. 
Table 2 Cardiovascular and other non-malignant diseases. Deaths in two periods

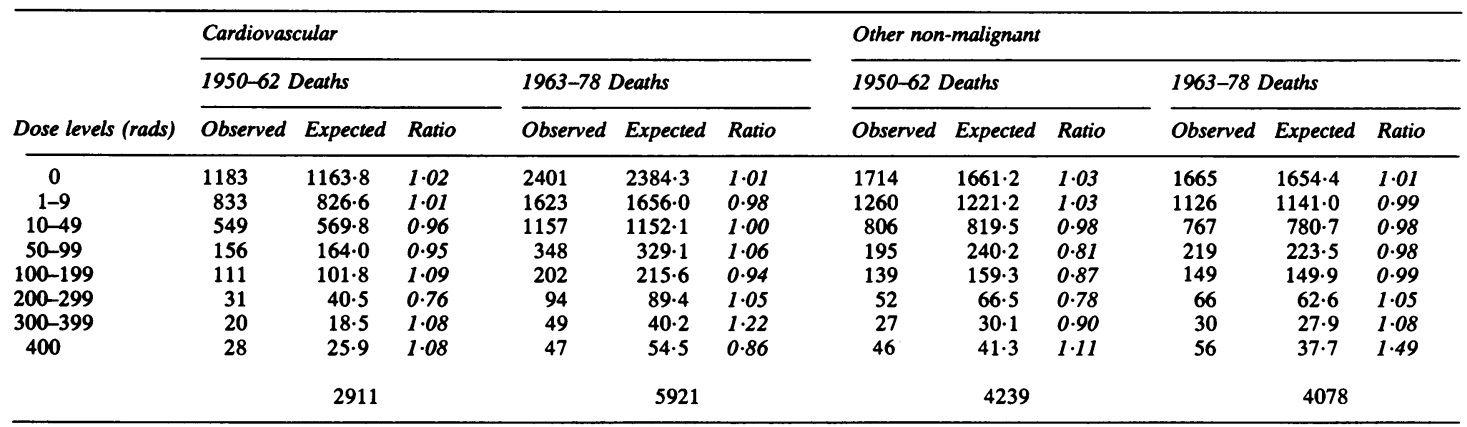

*ther non-malignant diseases include tuberculosis (1140), diseases of the digestive system (1822), diseases of blood and blood forming organs (132), and a residual group (5223). The cardiovascular diseases included cerebrovascular accidents (5108) and other diseases of the circulatory system (3724).

Table 3 Ratios of observed to expected deaths for two groups of non-malignant diseases and seven follow up periods

\begin{tabular}{|c|c|c|c|c|c|c|c|c|}
\hline \multirow[b]{2}{*}{ Diagnostic group } & \multirow[b]{2}{*}{ Dose levels* } & \multicolumn{7}{|c|}{ Follow up periods $\dagger$} \\
\hline & & 1 & 2 & 3 & 4 & 5 & 6 & 7 \\
\hline Cardiovascular diseases & $\begin{array}{l}1 \\
2 \\
3 \\
4 \\
5 \\
6 \\
7 \\
8\end{array}$ & $\begin{array}{r}109 \\
96 \\
91 \\
74 \\
126 \\
56 \\
82 \\
127\end{array}$ & $\begin{array}{r}101 \\
100 \\
101 \\
97 \\
94 \\
107 \\
95 \\
90\end{array}$ & $\begin{array}{r}98 \\
104 \\
96 \\
107 \\
105 \\
63 \\
137 \\
111\end{array}$ & $\begin{array}{r}92 \\
105 \\
102 \\
130 \\
100 \\
86 \\
140 \\
64\end{array}$ & $\begin{array}{r}98 \\
101 \\
106 \\
90 \\
99 \\
101 \\
137 \\
68\end{array}$ & $\begin{array}{r}106 \\
94 \\
93 \\
113 \\
96 \\
113 \\
100 \\
106\end{array}$ & $\begin{array}{r}105 \\
95 \\
101 \\
92 \\
81 \\
113 \\
119 \\
123\end{array}$ \\
\hline Other non-malignant diseases & $\begin{array}{l}1 \\
2 \\
3 \\
4 \\
5 \\
6 \\
7 \\
8\end{array}$ & $\begin{array}{r}104 \\
103 \\
98 \\
72 \\
101 \\
65 \\
107 \\
107\end{array}$ & $\begin{array}{r}101 \\
101 \\
107 \\
83 \\
77 \\
83 \\
108 \\
123\end{array}$ & $\begin{array}{r}105 \\
107 \\
89 \\
90 \\
82 \\
90 \\
46 \\
103\end{array}$ & $\begin{array}{r}97 \\
101 \\
100 \\
106 \\
98 \\
131 \\
118 \\
108\end{array}$ & $\begin{array}{r}100 \\
104 \\
96 \\
92 \\
114 \\
50 \\
91 \\
152\end{array}$ & $\begin{array}{r}99 \\
97 \\
100 \\
98 \\
97 \\
127 \\
108 \\
198\end{array}$ & $\begin{array}{r}107 \\
93 \\
96 \\
95 \\
90 \\
109 \\
114 \\
165\end{array}$ \\
\hline
\end{tabular}

* See table 2 also linear scale in table 4.

†Follow up periods (1) 1950-54, (2) 1955-58, (3) 1959-62, (4) 1963-66, (5) 1967-70, (6) 1971-74, (7) 1975-78.



Fig 2 Non-cancer deaths of A-bomb survivors: cardiovascular disease in two periods. correlations were linearly proportional to the index numbers (see linear scale in table 4), and one for when the rank correlations were proportional to the square of the distance from the centre of the ranking (see quadratic scale in table 4). In this way there was one weight for testing linearity of dose response (or rising trend with rising dose) and one for measuring U-shaped curvature of dose response (or oppositely directed slopes at high and low dose levels).

\section{Results}

For the group which included all the infection deaths there was, for each of the seven follow up periods shown in table 3 , a dip in the middle of the dose range of observed to expected ratios, also a strong hint of a significant difference between deaths before 1963 and later deaths (fig 3). Therefore, not surprisingly, the rank correlation tests provided statistical confirmation of U-shaped curvature of dose response and linear trend (table 4). For the group of cardiovascular deaths there were no positive 
Table 4 Rank correlation tests for linear and quadratic dose response for two groups of non-malignant diseases

\begin{tabular}{|c|c|c|c|c|c|c|c|c|c|c|c|}
\hline \multirow[b]{2}{*}{ Diagnostic groups } & \multicolumn{2}{|c|}{ Dose level } & \multicolumn{7}{|c|}{ Ranking of $O: E$ ratios for deaths in 7 follow up periods } & & \\
\hline & $(1) \dagger$ & (2) $\ddagger$ & 1 & 2 & 3 & 4 & 5 & 6 & 7 & \multicolumn{2}{|c|}{ Average score } \\
\hline Cardiovascular diseases & $\begin{array}{l}1 \\
2 \\
3 \\
4 \\
5 \\
6 \\
7 \\
8\end{array}$ & $\begin{array}{l}6 \\
3 \\
1 \\
0 \\
0 \\
1 \\
3 \\
6\end{array}$ & $\begin{array}{l}6 \\
5 \\
4 \\
2 \\
7 \\
1 \\
3 \\
8\end{array}$ & $\begin{array}{l}6 \\
5 \\
7 \\
4 \\
2 \\
8 \\
3 \\
1\end{array}$ & $\begin{array}{l}3 \\
4 \\
2 \\
6 \\
5 \\
1 \\
8 \\
7\end{array}$ & $\begin{array}{l}3 \\
6 \\
5 \\
7 \\
4 \\
2 \\
8 \\
1\end{array}$ & $\begin{array}{l}3 \\
6 \\
7 \\
2 \\
4 \\
5 \\
8 \\
1\end{array}$ & $\begin{array}{l}6 \\
2 \\
1 \\
7 \\
3 \\
8 \\
4 \\
5\end{array}$ & $\begin{array}{l}5 \\
3 \\
4 \\
2 \\
1 \\
6 \\
7 \\
8\end{array}$ & $\begin{array}{l}4.57 \\
4.43 \\
4.29 \\
4.29 \\
3.71 \\
4.43 \\
5.86 \\
4.43\end{array}$ & \\
\hline $\begin{array}{l}\text { Spearman's rank } \\
\text { Correlation coefficient }\end{array}$ & \multicolumn{2}{|c|}{$\begin{array}{l}\text { (1) linear } \\
\text { (2) quadratic }\end{array}$} & $\begin{array}{r}0.000 \\
+0.548\end{array}$ & $\begin{array}{l}-0.381 \\
-0.214\end{array}$ & $\begin{array}{l}+0.524 \\
+0.214\end{array}$ & $\begin{array}{l}-0.190 \\
-0.405\end{array}$ & $\begin{array}{l}-0.095 \\
-0.285\end{array}$ & $\begin{array}{l}+0.714 \\
+0.071\end{array}$ & $\begin{array}{l}-0 \cdot 167 \\
+0 \cdot 667\end{array}$ & $\begin{array}{l}+0.058 \\
+0.085\end{array}$ & $\pm 0 \cdot 143$ \\
\hline $\begin{array}{l}\text { Other non-malignant } \\
\text { diseases }\end{array}$ & $\begin{array}{l}1 \\
2 \\
3 \\
4 \\
5 \\
6 \\
7 \\
8\end{array}$ & $\begin{array}{l}6 \\
3 \\
1 \\
0 \\
0 \\
1 \\
3 \\
6\end{array}$ & $\begin{array}{l}6 \\
5 \\
3 \\
2 \\
4 \\
1 \\
8 \\
7\end{array}$ & $\begin{array}{l}5 \\
4 \\
6 \\
3 \\
1 \\
2 \\
7 \\
8\end{array}$ & $\begin{array}{l}7 \\
8 \\
3 \\
4 \\
2 \\
5 \\
1 \\
6\end{array}$ & $\begin{array}{l}1 \\
4 \\
3 \\
5 \\
2 \\
8 \\
7 \\
6\end{array}$ & $\begin{array}{l}5 \\
6 \\
4 \\
3 \\
7 \\
1 \\
2 \\
8\end{array}$ & $\begin{array}{l}4 \\
2 \\
5 \\
3 \\
1 \\
7 \\
6 \\
8\end{array}$ & $\begin{array}{l}5 \\
2 \\
4 \\
3 \\
1 \\
6 \\
7 \\
8\end{array}$ & $\begin{array}{l}4.71 \\
4.43 \\
4.00 \\
3.29 \\
2.57 \\
4.29 \\
5.43 \\
7.29\end{array}$ & \\
\hline $\begin{array}{l}\text { Spearman's rank } \\
\text { Correlation coefficient }\end{array}$ & \multicolumn{2}{|c|}{$\begin{array}{l}\text { (1) linear } \\
\text { (2) quadratic }\end{array}$} & $\begin{array}{l}+0.214 \\
+0.738\end{array}$ & $\begin{array}{l}+0.268 \\
+0.690\end{array}$ & $\begin{array}{l}-0.452 \\
+0.548\end{array}$ & $\begin{array}{l}+0.738 \\
-0.095\end{array}$ & $\begin{array}{l}-0.048 \\
+0.405\end{array}$ & $\begin{array}{l}+0.619 \\
+0.429\end{array}$ & $\begin{array}{l}+0.595 \\
+0.595\end{array}$ & $\begin{array}{l}+0.276^{*} \\
+0.473^{* *}\end{array}$ & $\pm 0 \cdot 143$ \\
\hline
\end{tabular}

*p<0.05; **p<0.01.

t Linear scale (see table 1).

‡Quadratic scale (see text).

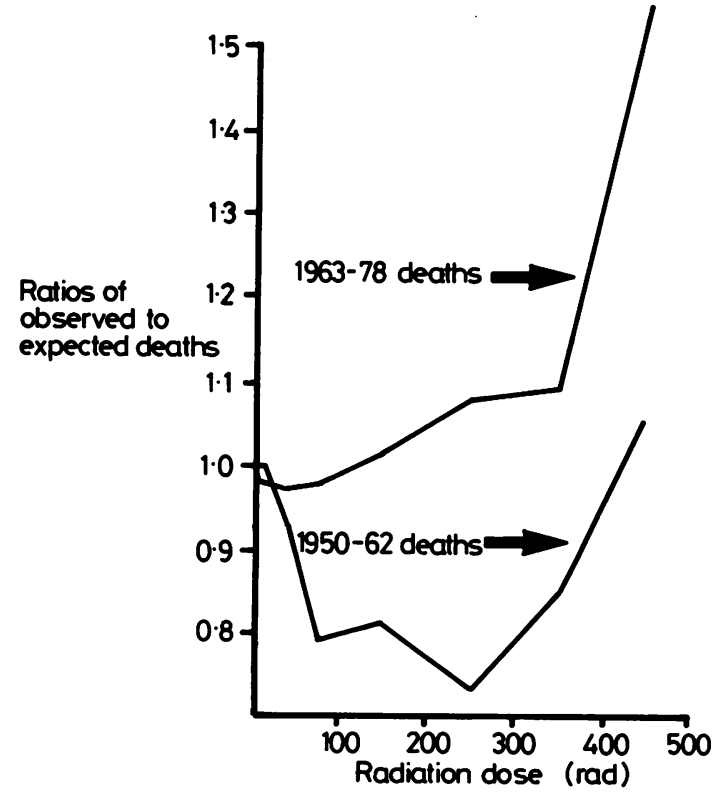

Fig 3 Non-cancer deaths of A-bomb survivors excluding cardiovascular deaths and trauma. findings, only an impression of a small deficit of deaths among recipients of more than 100 and less and 400 rads.

\section{Discussion}

The devastation caused by the Hiroshima and Nagasaki bombs radiated in every direction from two central points or hypocentres. Therefore, all effects of the explosions (including damage to property as well as damage to individuals) were dose related via hypocentre distances. As a result of the damage to property even those who were in no danger of blast injuries, radiation burns, or marrow damage-that is, low dose survivors-were at high risk of an infection death during the autumn and winter of 1945 and for an unknown period thereafter. This general hazard was dose related and obviously greater for people with low than high levels of immunological competence. On the assumption, therefore, that it took at least two years for living conditions in the two cities to revert to normal, we would expect, firstly, that low dose groups of any survivor population would have a reduced risk of dying from infections and, secondly, that this healthy survivor effect would not last for ever.

If selection effects of the early deaths had been the only persistent non-cancer effect of the bombing, 
high dose groups of the study population would have recorded lower rates of infection mortality than low dose groups. This was clearly not the case. It is reasonable, therefore to suggest that most survivors from acute effects of marrow were left with permanently scarred bone marrows that eventually caused some deaths from obscure blood diseases ${ }^{6}$ and a much larger number of fatal infections.

There are obvious reasons why we cannot be certain that this is what actually happened. Nevertheless, we now know enough to be reasonably certain that all RERF risk estimates for cancer effects of radiation are based on false assumptions concerning some of the non-cancer deaths, and that rectification of these mistakes will necessarily affect their estimates of cancer effects and might bring them into line with estimates based on radiation workers. ${ }^{5}$ There is clearly a need for more certainty on these matters and, in our opinion, this could be achieved by epidemiologists with access to RERF data (1) obtaining separate identification of all infection deaths; (2) linking all deaths after 1950 with medical records for earlier years; and (3) applying to the full complement of data statistical methods which are suitable for solving the following problems: different reactions of high and low dose survivors to the basic causes of infection deaths; threshold dose effects of the radiation; and possible conflict between nonthreshold dose effects of radiation (such as mutations) and exclusively high dose effects (such as tissue damage).
This investigation was supported by a grant from the International Radiation Research and Training Institute (IRRTI).

\section{References}

${ }^{1}$ Beebe GW, Land CE, Kato $H$. The hypothesis of radiation-accelerated aging and the mortality of Japanese A-bomb victims. In: Late biological effects of ionizing radiation, 1978; 3-35. (IAEA-SM-224/601).

${ }^{2}$ Beebe GW, Kato H, Land CE. Mortality experience of atomic bomb survivors 1950-74. Hiroshima, Japan: Radiation Effects Research Foundation, 1977. (Life Span Study report 8, RERF TR 1-77).

${ }^{3} \mathrm{~K}$ ato $\mathrm{H}$, Schull WJ. Cancer mortality among atomic bomb survivors 1950-78. Hiroshima, Japan: Radiation Effects Research Foundation, 1980. (Life Span Study report 9, with supplementary tables. RERF TR 12-80.)

${ }^{4}$ International Commission on Radiation Protection. Radiation protection. ICRP No 26. Oxford: Pergamon Press, 1977.

${ }^{5}$ Kneale GW, Mancuso TF, Stewart AM. Hanford radiation study III: a cohort study of the cancer risks from radiation to workers at Hanford (1944-77 deaths) by the method or regression models in life-tables. Br J Ind Med 1981; 38: $156-66$.

${ }^{6}$ Stewart AM. Delayed effects of A-bomb radiation: a review of recent mortality rates and risk estimates for five year survivors.J Epidemiol Community Health 1982; 36: 80-6, 1983; 37: 85-8.

${ }^{7}$ Stewart AM. Reply to letter by M E Ginevan and J S Puskin. J Epidemiol Community Health 1983; 37: 86-8.

${ }^{8}$ Ohkita T. Acute effects. $J$ Radiat Res: a review of thirty years of study of Hiroshima and Nagasaki atomic bomb survivors. 1975 ; 16, suppl: 49-66.

${ }^{9}$ Stuart A, Kendall MG. Robust and distribution-free procedures. In: The advanced theory of statistics. Vol 2. London: Guffin and Co Ltd, 365-512. 